\title{
LIBRAS E IMPLANTE COCLEAR: CONTRADIÇÃO OU COMPLEMENTARIDADE?
}

\author{
Lilian Cristine Ribeiro Nascimento ${ }^{1}$
}

Cibelle Carlos Sousa Lima ${ }^{2}$

\section{Resumo}

Este artigo tem como objetivo verificar os motivos que levaram alguns pais de surdos a fazerem a opção concomitante pela cirurgia do Implante Coclear e à exposição à Língua Brasileira de Sinais. A metodologia da pesquisa é a abordagem histórico crítica e a análise psicanalítica-hermenêutica de 8 entrevistas com pais e/ou mães de crianças matriculadas em uma escola bilíngue para surdos. Os autores que embasam as análises são Freud e outros da psicanálise, os quais nos ajudam a compreender os motivos subjetivos que direcionam os desejos e decisões dos pais; e, também, Michel Foucault que, com seus estudos, nos ajuda a compreender a emergência de novos sujeitos e discursos de verdade. Nossa conclusão é de que, ao optar por uma abordagem dupla e simultânea das possibilidades, as famílias as consideram complementares e, com isto, estão exercendo seu papel sociocultural como pais. Os resultados apontam para a emergência de um novo sujeito surdo, o implantado bilíngue, que demanda novas possibilidades educacionais.

Palavras-chave: Implante Coclear; Educação Bilíngue para Surdos; Psicanálise; Subjetividade; Análise de Discurso

\footnotetext{
${ }^{1}$ Fonoaudióloga pela Pontifícia Universidade Católica de Campinas, Mestre e Doutora em Educação pela Universidade Estadual de Campinas, Docente no Departamento de Psicologia da Universidade Estadual de Campinas. Endereço: Rua Bertrand Russell, 801, Cidade Universitária Zeferino Vaz, Campinas - SP, Brasil. CEP: 13083-865. Endereço eletrônico: lcrn05@yahoo.com.br

${ }_{2}^{2}$ Pedagoga pela Universidade de Santo Amaro/Unisa, de São Paulo, Mestre em Educação pela Faculdade de Educação da Universidade de São Paulo /FEUSP, Coordenadora Pedagógica. Endereço: Rua Bertrand Russell, 801, Cidade Universitária Zeferino Vaz, Campinas - SP, Brasil. CEP: 13083-865. Endereço eletrônico: cibellecslima2014@gmail.com
} 


\section{INTRODUÇÃO}

Este artigo tem como objetivo verificar os motivos que levam os pais de surdos a fazerem a opção concomitante pela cirurgia do Implante Coclear e à exposição à Língua Brasileira de Sinais. Esta prática, que há pouco tempo era rechaçada pelos profissionais da saúde, uma vez que o Implante Coclear era uma medida com vistas unicamente à oralização, tem se tornado mais comum na atualidade. É possível hoje encontrar famílias que optam por implantarem seus filhos surdos e, ao mesmo tempo, expô-los à uma educação bilíngue. Para compreender esta escolha dos pais, analisamos as respostas a entrevistas realizadas com pais e mães de crianças surdas a respeito da opção que fizeram para seus filhos no que se refere às possibilidades de reabilitação e educação destas crianças, marcadas pela escolha simultânea de submetê-los à cirurgia do Implante Coclear e à exposição à Língua Brasileira de Sinais. Foram realizadas 8 entrevistas com pais e/ou mães de crianças matriculadas em uma escola bilíngue para surdos localizada em um município da grande São Paulo. A idade das crianças varia entre 3 a 11 anos.

O Implante Coclear é um procedimento cirúrgico indicado para surdez profunda bilateral quando o indivíduo não se beneficia com as próteses auditivas convencionais, e tem a finalidade de desenvolver a linguagem oral. Tal medida fundamenta-se na ideia de que as pessoas surdas devem desenvolver a linguagem oral para sua inserção social, comunicativa e profissional. Contudo, o procedimento é rechaçado por uma parcela da comunidade surda, sendo considerado uma negação tanto do seu modo de ser no mundo, quanto de sua identidade surda (REZENDE, 2013).

Em 10 de junho de 2014, o Ministério da Saúde promulgou a portaria No 18 que determinou a incorporação dos procedimentos relativos à assistência hospitalar à saúde auditiva (Implante Coclear e prótese auditiva ancorada no osso) no Sistema Único de Saúde SUS. Desta forma, mais pessoas surdas estão tendo acesso à cirurgia do Implante Coclear no Brasil.

A proposta de Educação Bilíngue defendida pela comunidade surda, e utilizada na escola onde se realizou esta pesquisa, afirma a importância da Língua Brasileira de Sinais como primeira língua do surdo e a aprendizagem da Língua Portuguesa como segunda língua. 
A Educação Bilíngue de surdos envolve a criação de ambientes linguísticos para a aquisição da Libras como primeira língua (L1) por crianças surdas, no tempo de desenvolvimento linguístico esperado e similar ao das crianças ouvintes, e a aquisição do português como segunda língua (L2). (THOMA et al, 2014, s/p).

Descritas como metodologias diferentes, o Implante Coclear, que se define como recurso para o desenvolvimento da língua oral e a Educação Bilíngue, que prioriza a língua de sinais como língua de instrução e constituição linguística do sujeito surdo, a opção pelas duas formas simultaneamente parece paradoxal. No atual estudo, destacamos como objetivo geral, a busca por compreender porque a escolha simultânea do Implante Coclear e da Educação Bilíngue foi realizada pelas famílias entrevistadas. Temos, ainda, como objetivos específicos verificar como os discursos dos profissionais da saúde e da educação influenciaram a decisão das famílias, quais as tensões vivenciadas neste processo e como as duas línguas (oral e de sinais) vêm se estabelecendo na relação familiar.

O quadro abaixo descreve as características destes alunos em relação à idade atual, idade em que realizou a cirurgia e há quanto tempo, além do resultado na oralização.

\section{Quadro 1. Caracterização dos alunos cujos pais foram entrevistados}

\begin{tabular}{|l|l|l|l|l|}
\hline \multicolumn{1}{|c|}{$\begin{array}{c}\text { Criança / } \\
\text { idade }\end{array}$} & $\begin{array}{c}\text { Quem respondeu } \\
\text { à entrevista }\end{array}$ & $\begin{array}{c}\text { Idade em que } \\
\text { fez o IC }\end{array}$ & $\begin{array}{c}\text { Há quanto tempo } \\
\text { realizou o IC }\end{array}$ & Resultado em relação à oralização \\
\hline $\begin{array}{l}\text { B. e N. } \\
\text { gêmeas) } \\
3 \text { anos }\end{array}$ & Mãe & 2 anos e meio & 5 meses & Emissão de palavras \\
\hline $\begin{array}{l}\text { C. } \\
3 \text { anos }\end{array}$ & Pai & 2 anos & 1 ano & $\begin{array}{l}\text { Atende quando chamada pelo nome, } \\
\text { mas não emite nenhuma palavra }\end{array}$ \\
\hline $\begin{array}{l}\text { V. } \\
\text { anos }\end{array}$ & Pai e Mãe & 3 anos & 1 ano & Emissão de palavras \\
\hline $\begin{array}{l}\text { M. I. } \\
3 \text { anos }\end{array}$ & Pai e Mãe & 2 anos & 1 ano & Emissão de palavras \\
\hline $\begin{array}{l}\text { L. } \\
11 \text { anos }\end{array}$ & Mãe & 1 ano e meio & 10 anos & Não desenvolveu a linguagem oral \\
\hline $\begin{array}{l}\text { P. } \\
6 \text { anos }\end{array}$ & Mãe & 6 anos & 1 ano & Não desenvolveu a linguagem oral \\
\hline $\begin{array}{l}\text { R. } \\
\text { anos e } \\
\text { meio }\end{array}$ & Mãe \\
\hline $\begin{array}{l}\text { N. } \\
\text { anos e } \\
\text { meio }\end{array}$ & Pai & 2 anos & 3 anos & Emissão de palavras e frases \\
\hline
\end{tabular}




\section{1 O referencial metodológico}

Segundo Freitas (2007), as principais características da abordagem sócio histórica da pesquisa qualitativa são:

- Texto/Sujeito - objeto da pesquisa - são compreendidos em seu contexto;

- Questões e Fenômenos são compreendidos em seu acontecimento histórico;

- A coleta de dados tem como ênfase a compreensão - apoiada na descrição procurando as possíveis relações do evento em uma integração individual com o social;

- A atividade do pesquisador é entendida como um processo de transformação e mudança; é a reconstrução de sua história e de seu desenvolvimento;

- O pesquisador é entendido como um instrumento, ele é parte integrante da investigação: constrói-se a partir do lugar sócio-histórico que ocupa e depende das relações intersubjetivas que estabelece. O critério para identificação é a participação ativa e profunda: re-significar, refletir, aprender com o processo da pesquisa.

Assim, com base nessas considerações, esta pesquisa insere-se no campo das ciências humanas e da educação e, compreendendo que nossa pesquisa busca a correlação entre esses campos de estudo, buscando a complementariedade e compreensão dos fenômenos reais com os dados subjetivos, optamos por desenvolver nosso trabalho como uma pesquisa-ação, de abordagem histórico-crítica e de análise psicanalítica hermenêutica.

A psicanálise é utilizada como um instrumento de pesquisa para pensar a condição humana diante das adversidades experimentadas durante a vida. Freud propõe, desde o início de sua atividade como médico, aliar o tratamento à investigação. Sua prática, portanto, sempre esteve pautada na investigação, o que fez dele, não só um clínico, mas também, e principalmente, um teórico. A psicanálise, portanto, neste artigo, é convocada para a investigação e compreensão de fenômenos sociais e subjetivos.

Aliada à psicanálise, também a hermenêutica é convocada como possibilidade interpretativa dos textos (objeto da pesquisa), diretos e indiretos, bem como uma possibilidade de aprofundamento entre os discursos das famílias (texto/objeto), o texto da pesquisa e a linha de pensamento das autoras. 
As entrevistas foram realizadas com familiares (pai, mãe ou ambos) de crianças matriculadas em uma escola bilíngue para surdos, pela coordenadora pedagógica. Portanto, os pais mantinham uma relação de confiança com o entrevistador. Foram selecionadas famílias cujos filhos faziam uso de Implante Coclear. As entrevistas foram filmadas e posteriormente transcritas. Os pais assinaram o termo de consentimento para uso dos dados em pesquisa.

A seguir, organizamos trechos das entrevistas em blocos por assuntos, a fim de analisarmos os enunciados e refletirmos sobre as escolhas destas famílias sobre a educação de seus filhos.

\section{O DIAGNÓSTICO DA SURDEZ E A DECISÃO PELO IMPLANTE COCLEAR}

Em nossa amostra, o momento do diagnóstico da surdez é descrito como uma grande tragédia na vida dessas famílias. Sendo todos ouvintes, o nascimento de um filho surdo se apresenta como uma grande ferida narcísica, ou seja, um sofrimento por gerar uma criança diferente a eles próprios. Vejamos nos excertos abaixo como os pais narram este momento:

\section{Quadro 2: Enunciados sobre o diagnóstico}

Aí deram que elas tinham uma perda profunda até então, o primeiro impacto, normal, a gente sabia, eu sabia, mas a gente não queria acreditar, então tive que descobrir que era verdade, fato mesmo. (Entrevista 1)

Não é o padrão entre aspas assim normal que a gente descobre que o nosso filho tem um diferencial. Depois que passa esse susto inicial, aí a gente vai correr atrás do que a gente tem que fazer, porque é um mundo que a gente não conhece até então. (Entrevista 2)

A gente descobriu na verdade, desconfiava quando ele tinha uns 8 meses. Só que a gente não quer acreditar e ele balbuciava, ele falava mamãe, papai, e ficava por aí. Até que a gente tem, ele tem um priminho que tinha a mesma idade dele e falava e ele não era igual. A gente percebia que não era igual. Aí a gente pegou e pediu para a pediatra encaminhamento para o otorrino, encaminhamento, e ela não quis dar. Ah, mas você é doida, ele tá desenvolvendo normal. E aí a gente foi por conta própria atrás do exame e aí a gente descobriu... (Entrevista 3) 
Para mim foi bem difícil, chorei bastante. Para mim foi algo assim que eu não esperava mesmo. Para mim foi o fim. Chorei muito, muitos dias chorando. A gente descobriu com 9 meses e para mim foi muito difícil. (Entrevista 4)

Porque a gente não quer aceitar em primeiro assim, a gente nunca imagina, para mim foi bem difícil mesmo. (Entrevista 4)

Para mim, sinceramente, foi a pior notícia que eu recebi na minha vida, a médica falar para mim que ele era surdo. Eu já sabia, mas eu não queria acreditar. (Entrevista 6)

Quadro elaborado pelas autoras deste artigo, com trechos das entrevistas.

A dificuldade em acreditar no que há tempo já se percebia é referida nos enunciados: "A gente não quer acreditar"; "a gente sabia, eu sabia, mas a gente não queria acreditar". A esperança de estar enganado, de não ser real a perda de audição do filho mantém os pais numa situação de conflito, que adia o enfrentamento da realidade. O mecanismo de defesa, descrito por Freud (1976) como "denegação", é aqui percebido. Este mecanismo protege esses pais da dor, mantendo recalcada - fora do nível consciente - a realidade da surdez. O recalque afasta certos elementos do nível da consciência, como, por exemplo, nestes casos, a confirmação de uma alteração orgânica do filho. Nas palavras de Freud (1976, p. 113-4): "no caso de perigo externo, o organismo recorre à tentativa de fuga. O recalque (Verdrangung) é um equivalente dessa tentativa de fuga (inibições, sintomas e ansiedade)". Sendo negado, o elemento recalcado não deixa de existir, mas tem seu acesso impedido na consciência. Quando chega o diagnóstico, a dor se impõe e coloca estes pais diante de sua própria fragilidade. As palavras que definem este momento são: "chorei muito", "foi muito difícil", "um susto", "foi a pior notícia que eu recebi na minha vida", "foi um choque".

Segundo Mannoni (1988), quando uma mulher gera um bebê, ela reedita a própria infância. Ocorre uma regressão e uma identificação da mãe com o bebê. Essencial para a formação da subjetividade deste novo ser, a identificação materna se converte em cuidados essenciais para com ele, na amamentação, na higiene, nas palavras de ternura. Há uma esperança neste novo ser, uma idealização de que este pequenino ocupe o lugar de todas as frustrações vivenciadas pela mãe. "O esperado é que o filho retrate os seus ideais e que seja reconhecido pelos outros como máximo da perfeição e da beleza" (MANNONI, 1988, p. 18). 


\section{LIBRAS E IMPLANTE COCLEAR: CONTRADIÇÃO OU COMPLEMENTARIDADE?}

Ocorre que, quando o filho que nasce não corresponde ao idealizado, as esperanças se desmoronam.

A criança surda, porém, a princípio não é percebida como tal, caso não seja diagnosticada na maternidade. No caso da maioria das crianças cujos pais foram entrevistados, o diagnóstico não foi realizado nos primeiros dias de vida, mas alguns meses depois. Há um período de meses em que esses bebês corresponderam ao idealizado, e então, aos poucos aparece a desconfiança de que não escuta, quando não reage aos sons e não adquire a linguagem.

O adiamento do enfrentamento é, portanto, um mecanismo de defesa que se apresenta para manter o bebê real correspondente ao idealizado. Há um tempo entre a desconfiança da surdez e a ida ao médico, um prolongamento que mascara a realidade temida.

Por fim, o diagnóstico confirma o que se supunha, mas que se custava a acreditar. O que fazer, então, com a angústia de se ter um filho que não ouve? Como tamponar a dor, como lidar com o sofrimento? "A má formação do filho real faz reavivar seus conflitos e dificulta a elaboração gradual dos mesmos. A impossibilidade de realizar seus desejos, sonhos e fantasias traz uma grande frustração" (MARQUES, 1995, p. 122).

Logo após o diagnóstico, muitos dos pais recebem a informação de que o Implante Coclear (IC) pode ser realizado para solucionar o problema e esta parece uma possibilidade de dar a audição ao filho, de torná-lo "normal". A opção pelo Implante Coclear se apresenta como uma forma de trazer de volta o bebê idealizado.

\section{Quadro 3: A decisão pelo IC}

Aí depois disso o meu cunhado ele conhece, ele conhecia um médico do Hospital $X$, que ele foi diretor de lá, aí ele falou, ah J., tem como elas ouvirem ainda. Dá tempo, se você quiser fazer o Implante, dá. Aí a gente conseguiu através do Dr. N., do Hospital $X$, aí ele agilizou, como elas são pequenininhas, ele colocou na frente das crianças maiores e conseguiu fazer a cirurgia nas duas na mesma semana (Entrevista 1).

O próprio otorrino que a gente foi, logo de cara ele fez todo o acompanhamento, viu até que realmente a C. é surda bilateral, não tinha audição nenhuma, 100\% ausente a audição. Até que ele falou que a única opção que tinha na questão de audição seria 0 Implante Coclear. (Entrevista 2). 
Quando eu descobri foi até interessante, porque no dia a fono que deu o diagnóstico falou, ele é surdo mesmo, perda profunda, e aí vocês tem dois caminhos: ou vai para Libras ou você tenta fazer com que ele escute. Então falei, quero que ele escute, naquele primeiro momento, claro. Aí partimos para o aparelho auditivo convencional, não surtiu efeito, aí ela falou: o próximo passo é o Implante. (Entrevista 3)

Aí foi que ele levou numa consulta e o médico falou para ele, a sua filha ela é surdez profunda, para ela esse aparelho não adianta muito, ela vai ter que fazer Implante. (Entrevista 4)

Então fez uns testes, 6 meses, fez um teste durante 6 meses com aparelhos comuns de audição, sendo que o ganho foi pouco, então ela teve essa indicação de fazer esse Implante coclear com o doutor (...) e foi uma, nós apostamos nisso com todas as fichas, sabendo dos riscos que podiam ocorrer durante a cirurgia, e sabendo também que a cirurgia é o começo do processo. (Entrevista 5)

Para eles, o P. teria sido implantado com 3 anos, eu não me sentia segura, não era uma coisa que eu queria porque eu não tinha conhecimento sobre o Implante, eu não tinha noção de como era um Implante, então eu não quis, eu não aceitei. Foi quando me mandaram para o Hospital $X$, mesmo sem eu querer me mandaram para lá para eu estar conversando com os médicos e psicólogos, tudo, e eles me orientaram e me explicaram como funcionava o Implante. (Entrevista 6)

Então, a gente não pensou duas vezes. Eu queria ter implantado ele antes. (Entrevista 7) Se existe hoje possibilidade de você, se existe tecnologia de, que no caso é o Implante Coclear, ou o que o pessoal fala que é o ouvido biônico, não sei se é a mesma coisa, mas acho que o Implante Coclear deu essa outra opção a ele (Entrevista 8).

Quadro elaborado pelas autoras deste artigo, com trechos das entrevistas.

As famílias evidenciam em suas falas a influência do discurso médico e fonoaudiológico na decisão sobre o Implante Coclear. Esta decisão lhes parece acertada; ela possibilita, segundo lhes prometem os discursos médicos, que seus filhos sejam semelhantes a eles, e desenvolverem a mesma língua. Para Marques (1995, p. 123), "uma vez entendido que o filho representa para a mãe a reedição de sua própria infância, um filho anormal é como se fosse o seu retrato oposto". O desejo de reverter esse oposto em um igual a eles, os mobiliza para a decisão do Implante Coclear. 
Porém, este não é o único discurso que permeia sua realidade após o diagnóstico e invade o imaginário dos pais. Além deste, o discurso pedagógico, que nestas famílias indicou a necessidade de uma Educação Bilíngue, faz confronto e se impõe aos pais. Vejamos como estes discursos se refletiram nas decisões dos pais.

\section{A FAMÍLIA E A CRIANÇA SURDA ENTRE DOIS DISCURSOS DE PODER}

Conforme a amostra de nossa pesquisa evidencia, as famílias vivem entre dois principais discursos de poder-saber: o discurso médico e o discurso pedagógico.

Em ambos os discursos, seja o discurso médico/fonoaudiológico (neste caso materializado em torno do Implante Coclear), seja o discurso educacional/pedagógico (neste caso materializado em torno da Educação Bilíngue - Língua de Sinais), a investida em torno dos benefícios e das potencialidades de suas técnicas e saberes é, praticamente, imediata ao diagnóstico da surdez. Cada família decide o que fazer e qual caminho seguir, mas são fortemente influenciadas pelos discursos a que são expostas. Entretanto, encontramos ainda no contexto da pesquisa um terceiro discurso de poder-saber (que podemos considerar um discurso indireto), igualmente forte em sua influência sobre as famílias: o poder-saber jurídico/legislativo representado pelo Estado. Tal discurso visa definir normas legais, características de atendimento institucional, direitos e deveres das famílias e de seus filhos.

\footnotetext{
Embora usando várias denominações, a legislação brasileira é considerada, pela Organização das Nações Unidas (ONU) e pela Organização dos Estados Americanos (OEA), uma das mais amplas do mundo visando proteger o direito das pessoas com deficiência. (...) Normas gerais que amparam todos os cidadãos, normas que visam às pessoas deficientes e normas específicas dirigidas às pessoas com deficiência auditiva, todas protegem o surdo e devem ser aplicadas em seu benefício. (LIBERALESSO \& LIBERALESSO, 2011, p. 12 e 13).
}

No caso de nossa pesquisa, as 8 famílias optaram por uma abordagem dupla, confiando em sua complementaridade. Para melhor abrangência e pertinência da análise desta opção das famílias, retornamos, a seguir, a alguns referenciais teóricos.

\subsection{Entre o normal e o anormal - discursos de normalização e poder}


Em seus estudos Foucault aponta que o processo de "normalização", que se desenvolveu em nossa sociedade a partir do século XVIII, manifestou seus domínios em diversas esferas e instituições sociais: na educação, na medicina, na produção industrial e no exército. Foucault (2001, p. 62) analisando o célebre estudo "O normal e o patológico" de Canguilhem (1995), enfatiza três ideias importantes a respeito da norma: 1. Ela se manifesta em vários domínios - educação, medicina, indústria e exército; 2. Ela legítima o exercício do poder; 3. Ela traz consigo os princípios de qualificação e correção. Ora, neste conjunto de ideias enfatizadas por Foucault podemos compreender facilmente o papel da norma em nossa sociedade: a norma tem seus desígnios para o poder e tem uma intenção de intervir e transformar a sociedade positivamente. Nas palavras do autor:

\begin{abstract}
é esse conjunto de ideias que eu gostaria de tentar aplicar historicamente, essa concepção ao mesmo tempo positiva, técnica e política da normalização [...] Pareceme um erro ao mesmo tempo metodológico e histórico considerar que o poder é essencialmente um mecanismo negativo de repressão; que o poder tem essencialmente por função proteger, conservar ou reproduzir relações de produção. [...] Descrevendo assim o poder, parece-me que, no fundo, ainda se está utilizando um modelo historicamente superado [...] O que o século XVIII instaurou mediante o sistema "disciplina-normalização", parece-me ser um poder que, na verdade, não e repressivo, mas produtivo [...] (FOUCAULT, 2001, p. 62-64, aspas do original).
\end{abstract}

Os discursos de verdade, os procedimentos e os princípios normalizadores das instituições moldaram nossa sociedade e os processos formativos das subjetividades dos sujeitos. Neste cenário, sujeitos anteriormente anulados ou excluídos passam a ganhar espaço e visibilidade na sociedade, como é o caso das crianças, do louco, dos deficientes, enfim, dos ditos "anormais". Trataremos aqui do caso específico das crianças e da produção de sua infância, à luz de um breve recorte dos discursos de poder-saber.

$\mathrm{O}$ argumento de Foucault corrobora com nossa análise na medida em que ele esclarece que foi através da família que os discursos de poder exerceram seus domínios sobre as crianças. Ou seja, a família absorveu os discursos ao seu redor e, na formação familiar, os discursos da medicina e da educação foram decisivos para influenciar o modo como as famílias criam, cuidam e educam suas crianças.

Os pais têm de cuidar dos filhos, os pais têm de tomar conta dos filhos, nos dois sentidos: impedir que morram e, claro, vigiá-los e, ao mesmo tempo, educá-los. A vida futura das crianças está nas mãos dos pais. [...] É a idéia de uma educação tal que, em primeiro lugar, seria inteiramente, ou no essencial, confiada aos próprios pais, que são os educadores naturais dos filhos. [...] Mas educação natural também 
quer dizer o seguinte: essa educação deve obedecer a certo esquema de radicalidade, deve obedecer a certo número de regras que, precisamente, devem garantir a sobrevivência das crianças, de um lado, e sua educação e desenvolvimento normalizado, do outro. Ora, essas regras e a racionalidade dessas regras são detidas por instâncias como os educadores, como os médicos, como o saber pedagógico, como o saber médico. Em suma, toda uma série de instâncias técnicas que balizam e sobrepujam a própria família. (FOUCAULT, 2001, p. 323 e 324).

O que o autor nos alerta é o fato de que, a partir do fim do século XVIII, a formação familiar fica compactada e fragilizada, sujeita a qualquer tipo de poder, como o poder da medicina e da educação que, ao lado do Estado, disputam com a família o corpo da criança. Estes discursos de poder-saber pedem às famílias que lhes confiem seus filhos para que se façam deles saudáveis, úteis, com boa instrução, desempenho e aptidão.

Enfim, a infância, como fase de desenvolvimento histórica do sujeito, e, historicamente marcada a partir deste período e dessas transformações, até os dias de hoje, tornou-se o grande objeto e instrumento da medicina e da educação, que em suas práticas e em seus discursos produzem intervenções positivas e benéficas às crianças com vistas ao seu desenvolvimento total e sua inserção normatizada e controlada na sociedade. Tanto a medicina (principalmente nas áreas da psique humana como a psiquiatria) quanto a educação (principalmente através da escola) e o Estado (estabelecendo das diretrizes de direitos e deveres na sociedade moderna) normatizam, analisam, moldam e controlam o comportamento das crianças (nós acrescentaríamos, ironicamente, com boas intenções!).

De volta à questão central, a respeito da análise da opção das famílias pelo Implante Coclear e pela Educação Bilíngue/Língua de Sinais, simultaneamente, uma análise foucaultiana desta problematização nos permitiria dizer que o poder-saber médico, o podersaber da escola e o poder-saber estatal (enquanto instituições de normalização e controle) disputam o corpo da criança, todos em busca do exercício de poder positivo. Como vimos, há séculos estes discursos de saber se constituem de modo aparentemente independente, mas que, na verdade, funcionam como um "pano de fundo" da formação e do controle social, familiar e das forças produtivas.

Levando-se em conta os grandes benefícios que sejam alcançados com a real inclusão das pessoas com deficiência na vida social, econômica e política, a consciência de toda população deve ser despertada e os governos devem garantir o respeito aos direitos já conquistados por esses indivíduos. Segundo as normas 
jurídicas e os Tratados Internacionais atuais, as pessoas deficientes têm assegurado o direito de exercer, em condições de igualdade com os demais indivíduos, todos os direitos civis, políticos, econômicos, sociais e culturais. (LIBERALESSO \& LIBERALESSO, 2011, p. 54).

À luz destes referenciais, a criança surda se constitui como sujeito anormal nos três contextos: no contexto médico, a anormalidade biológica da surdez e a busca de sua correção através das tecnologias de Implante Coclear e de estimulação auditiva para a oralização; no contexto escolar, a anormalidade linguística é que precisa ser "corrigida" para que a criança tenha um desenvolvimento moral, social e cultural; no contexto jurídico, a anormalidade da deficiência como "incapacidade ou desvantagem" do sujeito deve ser assistida pelo Estado garantindo-lhe igualdade nos direitos civis e amparo no atendimento dos serviços estatais. De maneira "grotesca", os três contextos consideram a criança surda um "anormal" e buscam convencer as famílias a lhes confiarem seus filhos para a "normalização", oferecendo técnicas positivas, isto é, em ambos os contextos, a oferta beneficiaria a criança na sua interação com a sociedade.

Ora, visto desta maneira e em nossa análise, ao optarem por aceitar o benefício de cada área, de cada poder, as famílias estão conquistando processos importantes: primeiro exercem sua subjetividade em torno de uma decisão que visa o cuidado com o filho, e, consideramos o cuidado de si e do outro uma importante ferramenta do desenvolvimento humano; em seguida, desconstroem a noção de que os efeitos de poder caracterizam-se, necessariamente, como negativos. A alternativa, da absorção do conjunto destes dois ou mais saberes e seus respectivos poderes, representa o fortalecimento da subjetividade destas famílias e uma possibilidade de autointerpretação de sua existência como sujeitos historicamente produzidos; haja visto que em outros momentos históricos as famílias tornavam-se "reféns" de um único discurso de poder-saber o que resultava na produção de sujeitos pacientes ou sujeitos incapazes, enfim, sujeitos excluídos da vida social e cultural.

Poderíamos dizer que estas famílias optam por encontrar a "terceira margem do rio" e estão colaborando em formar uma nova ordem de discurso.

\subsection{A terceira margem do rio - subjetividade, sujeição e o discurso "verdadeiro"}


Como um sujeito foi estabelecido, em diferentes momentos e em diferentes contextos institucionais, como objeto de conhecimento possível, desejável ou até mesmo indispensável? Como a experiência que se pode fazer de si mesmo e o saber que se pode fazer de si mesmo, e o saber que deles formamos, foram organizados através de alguns esquemas? (FOUCAULT, 1997b, p. 109)

A compreensão a que chegamos, a partir da análise dos discursos das famílias entrevistadas, sobre a formação de um novo discurso e um novo papel histórico, e, de certa maneira transformador, é fundamental para abordarmos a trama complexa de correlações entre processos de sujeição e os sujeitos que emergem como efeito da relação entre estes dois discursos de poder-saber.

[...] é preciso procurar saber como as relações de sujeição podem fabricar sujeitos. Do mesmo modo, melhor do que procurar a forma única, o ponto central de onde todas as fórmulas do poder derivam, por via de consequência ou de desenvolvimento, é preciso primeiro deixá-las aparecer na sua multiplicidade, nas suas diferenças, na sua especificidade, na sua reversibilidade: estudá-las, portanto, como relações de força que se entrecruzam, que remetem umas às outras, convergem ou, ao contrário, se opõem e tendem a se anular (FOUCAULT, 1997b, p. 71).

Conforme apontamos anteriormente, os dois discursos de poder saber (que se estabelecem em uma corrente de correlações de forças e se entrecruzam, se complementam) em torno da criança surda e sua família exercem forças que culminam na produção de um novo sujeito histórico: a criança surda implantada e usuária da língua de sinais.

O fio condutor que parece ser o mais útil, nesse caso, é constituído por aquilo que
poderia se chamar de "técnicas de si", isto é, os procedimentos, que, sem dúvida,
existem em toda civilização, pressupostos ou prescritos aos indivíduos para fixar sua
identidade, mantê-la ou transformá-la em função de determinados fins, e isso graças
a relações de domínio de si sobre si ou de conhecimento de si por si. Em suma, [...]
que fazer de si mesmo? Que trabalho operar sobre si? Como "se governar",
exercendo ações onde se é o objetivo dessas ações, o domínio em que elas se
aplicam, o instrumento ao qual podem recorrer e o sujeito que age?
(FOUCAULT, 1997c, p. 109-110, grifos nossos, aspas do original).

A primeira reflexão que traçamos, anteriormente a esse respeito, é a de que os poderes que influenciam esses sujeitos têm finalidades positivas, benéficas; a segunda reflexão desta problemática é a seguinte: a emergência deste posicionamento das famílias se dá, justamente, no cruzamento de dois discursos de poder-saber. Nesse sentido, podemos dizer que este sujeito foi desejado, foi produzido. Uma terceira reflexão nos leva a considerar que os elementos que compõe o discurso destas famílias trazem em seu bojo características culturais 
que foram secularmente construídas em nossa sociedade: o cuidado de si e do outro. A ideia e prática "do cuidado de si e do outro" como uma ferramenta de organização e formação social pode ser encontrada desde a Antiguidade até os nossos tempos, tendo a cada época histórica, sofrido algumas alterações e, talvez, ao longo dos tempos, tenha perdido destaque e importância em nossa civilização sem que, com isto, tenha perdido o seu valor fundamental. Segundo os estudos de Foucault (1997c) sobre a história do "cuidado de si", ele pode ser entendido como uma experiência e uma técnica que transforma a experiência (subjetivamente e, também, objetivamente - no que diz respeito a linguagem, ao trabalho, à vida social e cultural em geral). O que nos direciona para a quarta e última análise desta produção discursiva das famílias: ela potencializa a capacidade de "governo de si mesmo".

\begin{abstract}
A história do "cuidado" e das "técnicas" de si seria, portanto, uma maneira de fazer a história da subjetividade; porém, não mais através da separação entre loucos e não loucos, doentes e não doentes, delinqüentes e não delinqüentes, não mais através da constituição de campos de objetividade científica, dando lugar ao sujeito que vive, que fala, que trabalha. Mas através do empreendimento e das transformações, na nossa cultura, das "relações consigo mesmo", com seu arcabouço técnico e seus efeitos de saber. Seria possível, assim, retomar num outro aspecto a questão da "governamentalidade": o governo de si por si na sua articulação com as relações com o outro (como é encontrado na pedagogia, nos conselhos de conduta, na direção espiritual, na prescrição dos modelos de vida etc.) (FOUCAULT, 1997c, p. 111, aspas do original).
\end{abstract}

Não se trata de localizar o indivíduo em uma rede de poder e o isolar em uma classificação estanque, imutável. Trata-se de compreender como os sujeitos se articulam, se governam, em meio a multiplicidades de relações de poder-saber que os atravessam. Esta percepção tem como objetivo valorizar as subjetividades nos contextos sociais contemporâneos mediados pelas relações de poder-saber. Grande parte desta valorização se dá na produção, posição e ordem discursiva que o discurso de verdade destas famílias (objeto de estudo em nossa pesquisa) se materializam como produto da sujeição ao mesmo tempo em que, e contraditoriamente, possibilitam a instauração de uma nova ordem discursiva e, portanto, de uma outra e nova possibilidade de governamentalidade às famílias e suas crianças.

Ainda, a partir deste contexto clássico, Foucault aponta que esta cultura de si (e, consequentemente do cuidado e do conhecimento de si) se comportava de acordo com um conjunto de práticas que serviam a determinado objetivo, nas palavras do autor: "ora, de que precisamos para poder manter nosso domínio diante dos acontecimentos que podem se 
produzir? Precisamos de "discurso": de logö̈, entendidos como discursos verdadeiros e discursos racionais" (FOUCAULT, 1997d, p. 127, aspas do original).

Segundo os estudos de Foucault o instrumento que precisamos para nos "afrontar com o real" é o discurso verdadeiro e dele emergem três questões:

1. A questão de sua natureza, esta questão diz respeito ao conhecimento teórico que envolve o discurso:

convém assinalar aqui que os discursos verdadeiros de que precisamos não dizem respeito àquilo que somos, a não ser na nossa relação com o mundo, no nosso lugar na ordem da natureza, na nossa dependência ou independência em relação aos acontecimentos que se produzem. Não são, de forma alguma, uma decifração de nossos pensamentos, de nossas representações, de nossos desejos. (FOUCAULT, 1997d, p. 127).

2. A questão do modo de existência em nós desses discursos; para Foucault "a absorção de uma verdade dada por um ensinamento, uma leitura, ou um conselho; e ela é assimilada até que se torne uma parte de si mesmo, um princípio, interior, permanente e sempre ativo" (id.,1997d, p. 129);

3. Questões técnicas sobre os métodos dessa apropriação do discurso de verdade: importância de escutar, saber escutar o mestre ou um conselho; importância da escrita, a escrita pessoal como memória e reflexão, para constante leitura e reatualização; Importância de voltar-se para si, no sentido de memorizar o que foi aprendido e valorizar suas "riquezas".

Estas três questões emergentes podem ser encontradas nos discursos das famílias de nossa pesquisa e, justamente por isso, podemos perceber que não são apenas pensamentos e desejos individuais, mas uma ordem discursiva que, através de suas técnicas, está moldando os sujeitos, conforme as palavras a seguir:

\section{Quadro 4: Discurso sobre o IC}

Na verdade a decisão nossa hoje do $N$. estar implantado, é para que amanhã ele fale assim, olha eu não quero esse Implante, eu quero ser surdo mesmo, não quero ouvir. Mas pelo menos meus pais me deram a opção de repente ouvir pelo menos um retorno, algum barulho de alguma coisa. Isso ele tem. Se ele vai ser, lógico desde que, vai depender dele também para ele se tornar uma criança como outra qualquer. Mas se de repente amanhã ele falar eu não quero ouvir. Quero, optei pela primeira língua que é sinais, eu quero... Então é ele que vai tomar essa decisão. Então nós achamos que nesse primeiro momento tinha que dar essa oportunidade dele decidir. E se amanhã ele achar que não, ele tem uma pecinha dentro dele lá que vai de repente se ele quiser ouvir, tentar ouvir, ele vai 
ouvir, já está ouvindo graças a Deus, eu quero ouvir aquele passarinho cantar, ele vai colocar lá o aparelhinho aquele dia e vai ouvir. Então ele vai ter essa opção. E o que nos levou a tomar essa decisão mesmo foram os profissionais no início, que nos motivou. 0 próprio médico, ele falou, eu vou abrir a porta aqui, vai sair o médico e vai entrar o pai. Eu no lugar de vocês eu faria o Implante. Faz que vocês não vão se arrepender. Se ele amanhã achar que vocês, com certeza ele não vai te questionar no futuro. Pelo menos vocês deram a ele a chance, uma opção a mais para a sociedade aí. Então... (...) Novamente, e como eu disse, eu acho que o pai e a mãe têm que fazer, têm que dar essa chance aí para seu filho, essa alternativa, essa opção e amanhã ele vê o que é melhor. (Entrevista 8)

Quadro elaborado pelas autoras deste artigo, com trechos das entrevistas.

Os estudos foucaultianos nos conduzem a compreender que para exercer o cuidado de si (compreendendo também o conhecimento de si) "lançamos mão" de um conjunto de técnicas, de equipamentos e de instrumentos que nos levam a pensar sobre o pensamento como um exercício ou método de "afrontar o real" através dos discursos verdadeiros. Tal afrontamento nós conduzem a representar o futuro. Isto é, o exercício do cuidado de si, ao longo de toda a vida, correlaciona o que se passou e produz efeitos no presente, e, o que vivemos agora que produzirá efeitos do futuro. Não se trata de projetar ou adivinhar o futuro tal qual ele será de fato (até porque isto é impossível no contexto da investigação pelo pensamento), mas de exercitar o pensamento em torno de uma compreensão de si a partir dos processos de sujeição a que se foi submetido.

Esses exercícios de pensar, apontados pelo autor, podem se constituir: 1. Como uma meditação sobre os males futuros - não somente para antecipar males e sofrimentos, mas para nós acostumarmos com eles; 2. Como exercícios de privação ou resistência - estes têm a função de independência do indivíduo em relação ao mundo exterior; 3. Exercitar e Treinar o pensamento, conforme Foucault (1997d, p. 132), "trata-se de prescrever uma atitude hermenêutica em relação a si mesmo: decifrar o que pode haver de concupiscência nos pensamentos aparentemente inocentes".

Como vimos as famílias enunciam com clareza a história que passaram desde a notícia da surdez até o momento da cirurgia de Implante Coclear e do encaminhamento para uma educação escolar bilingue, bem como, suas expectativas com o futuro. Em nossa interpretação podemos assumir que, embora as falas (texto) das famílias enunciem-se como individuais, nossa pesquisa evidencia o caráter coletivo desta ordem discursiva e a tentativa de formular um pensamento em torno da compreensão de si e, ainda que de maneira inocente e imatura, 
este exercício de pensamento demonstra uma atitude hermenêutica sobre si e o conhecimento de si antecipando um possível processo de governamentalidade.

Tais exercícios de pensamento objetivam vincular os sujeitos aos discursos de verdade aos quais estão envolvidos, legitimando o surgimento destes novos sujeitos (com suas identidades, saberes e práticas) nas redes e tensões de poderes que se entrelaçam na sociedade. Enfim, aprendemos que as representações que se estabelecem destes sujeitos não revelam uma verdade que estava escondida, ao contrário, revelam as forças ou, dito de outro modo, "a voz" que fez emergir este sujeito e, portanto, não se trata de um indivíduo localizado e particular, mas de um sujeito social que, com seu surgimento, nos oferece uma oportunidade de repensar os princípios que nos formam, bem como, a formação de nossa sociedade. $\mathrm{O}$ trecho abaixo ilustra parte destas tensões, a afirmação de uma identidade e o exercício de discurso de uma das famílias:

\section{Quadro 5: Tensões}

Se ele não quiser, mais para frente, se o R. não quiser ouvir e só ele tirar. Tirou o aparelho, ele não escuta nada. Se ele quiser guardar, tudo bem, pode guardar, não escuta. Mas aí eu dei a opção para ele: quer ouvir um pouco e se você não quiser, você tira. (...) Porque a criança não decide. Ele vai decidir mais para frente. (...) É um telefone, é um barulho, é uma bomba, é alguém falando. Se assusta. São coisas que no cotidiano do surdo não tem, e é importante. Eu acho importante. Eu daria o conselho para implantar, se puder. Implantar, vai ter diferença. Não vai deixar de ser surdo, mas vai melhorar muito para ele mais para frente eu acho. (Trecho da entrevista 7)

Quadro elaborado pelas autoras deste artigo, com trechos das entrevistas

Podemos dizer que no discurso de verdade, o qual as famílias desta pesquisa apoiam e reproduzem, encontramos elementos que coincidem ou se encaixam nestes exercícios de pensar o real, apontados pelo autor. Nesse sentido, podemos afirmar que são, de fato, discursos de verdade e têm por finalidade dar sentido e organizar um modo de viver destas famílias. Enfim, nossa opção nesta pesquisa de correlacionar nosso argumento com os estudos teóricos de Foucault tem como objetivo questionar a realidade a partir de um recorte muito pontual de uma realidade e de prática existentes; e, também, neste nosso estudo, procedemos a análise deste novo discurso que se forma em nossa sociedade com vistas a justificar o posicionamento das famílias e, também, de apoiá-las. 
Selecionamos trechos da entrevista 6 e os relacionamos com os exercícios de análise do discurso sugeridos pelo autor.

\section{Quadro 6 - Discursos verdadeiros e subjetividade}

\begin{tabular}{|c|c|c|}
\hline $\begin{array}{l}\text { Exercício 1- Mediação de males } \\
\text { futuros }\end{array}$ & $\begin{array}{l}\text { Exercício } 2 \text { - privação ou } \\
\text { resistência }\end{array}$ & $\begin{array}{l}\text { Exercício } 3 \text { - exercitar e } \\
\text { treinar o pensamento }\end{array}$ \\
\hline $\begin{array}{l}\text { Mae só imagina coisa boa né, eu } \\
\text { espero que daqui... meu filho } \\
\text { está com 6, então daqui há } 10 \\
\text { anos meu filho este ja bem } \\
\text { como ele está hoje, que ele só } \\
\text { tenha a agradecer todo o } \\
\text { esforço que eu fiz, porque dia } \\
\text { após dia a gente vê que não é } \\
\text { fácil, tem muita gente } \\
\text { preconceituosa, muita gente } \\
\text { que não aceita. Então espero } \\
\text { que daqui há } 10 \text { anos esse } \\
\text { preconceito tenha acabado pelo } \\
\text { menos um pouquinho e que meu } \\
\text { filho esteja bem. Ele esteja já } \\
\text { a caminho, já ne, } 16 \text { anos, vai } \\
\text { terminar os estudos com } 16, \\
\text { então que ele não tenha puxado } \\
\text { a mãe, que ele vá além do que } \\
\text { ele possa ir. }\end{array}$ & $\begin{array}{l}\text { Então na minha opinião, eu } \\
\text { acho que todo mundo } \\
\text { deveria pelo menos tentar } \\
\text { porque surdo ele já é, } \\
\text { língua de sinais, ele já tem. } \\
\text { Então eu acho que não } \\
\text { custa nada implantar e } \\
\text { tentar. Eu acho que, não é } \\
\text { bem uma obrigação, mas é } \\
\text { uma coisa assim, que é uma } \\
\text { necessidade. Ninguém sabe } \\
\text { o dia de amanhã. }\end{array}$ & $\begin{array}{l}\text { Aí ela falou, N., você } \\
\text { descobriu que o P. é surdo } \\
\text { desde os } 3 \text { anos, o P. já } \\
\text { está com } 5 \text { anos. Quanto } \\
\text { tempo mais você vai } \\
\text { perder esperando que seu } \\
\text { filho fale? Seu filho não } \\
\text { tem nenhuma linguagem } \\
\text { para falar com você. Ele } \\
\text { não conversa com você. } \\
\text { Como você fala com seu } \\
\text { filho? Aí eu falei: fazendo } \\
\text { gestos. E aí ela falou: você } \\
\text { acha que o mundo vai } \\
\text { conversar com seu mundo } \\
\text { fazendo gestos? Foi onde } \\
\text { eu abri a minha mente, foi } \\
\text { onde eu vi que realmente } \\
\text { ela estava com razão e } \\
\text { tinha sentido o que ela } \\
\text { estava falando, foi onde } \\
\text { eu aceitei. }\end{array}$ \\
\hline
\end{tabular}

Quadro elaborado pelas autoras, com trechos das entrevistas.

Em uma perspectiva foucaultiana, podemos interpretar que estas famílias caminham para uma crítica de como foram constituídas para, quiçá no futuro, exercitar uma atitude de mudança e crítica sobre o lugar social, cultural e histórico que ocupam. Nesse contexto destacamos o papel fundamental da escola nos processos de subjetivação humana.

É mais do que óbvio o papel que a escola desempenhou nas transformações que levaram da sociedade de soberania para a sociedade estatal. Não é demais insistir que, mais do que qualquer outra instituição, a escola encarregou-se de operar as individualizações disciplinares, engendrando novas subjetividades e, com isso, 
cumpriu seu papel decisivo na constituição da sociedade moderna. A escola "foi sendo concebida e montada como a grande e (mais recentemente) a mais ampla e universal -máquina capaz de fazer, dos corpos, o objeto do poder disciplinar; e, assim, torná-los dóceis"; além do mais, a escola é, depois da família (mas, muitas vezes antes dessa), a instituição de sequestro pela qual todos passam (ou deveriam passar...) o maior tempo de suas vidas, no período da infância e da juventude. Na medida em que a permanência na escola é diária e se estende ao longo de vários anos, os efeitos desse processo disciplinar de subjetivação são notáveis. Foi a partir daí que se estabeleceu um tipo muito especial de sociedade, à qual Foucault adjetivou de disciplinar. (VEIGA-NETO, 2005, p. 84 e 85, aspas do original).

Talvez a escola contemporânea deva desempenhar um papel ainda mais decisivo de apoio e orientação das famílias e das crianças neste processo transformação e formulação da compreensão de si (ser) e de si com o mundo (estar) fundamentais em uma atitude de "governo de si" que, fortalecida pela multiplicidade das famílias, pode possibilitar o surgimento de um bio-poder. Neste sentido (do bio-poder) o atual desenvolvimento das tecnologias digitais de multimídia e de redes sociais ligadas à internet representam ferramentas importantes neste processo de organização e articulação das famílias entre si. Contudo este tema e seus aprofundamentos específicos não serão abordados neste artigo.

\subsection{Fonoaudiologia e Educação - Discursos convergentes?}

Estudos linguísticos demonstram que o processo de aquisição da língua de sinais é muito similar ao processo de aquisição da língua oral (QUADROS, 1997). Se a criança surda é estimulada e exposta à língua de sinais, desde bebê, ela irá se apropriar da língua naturalmente, ou seja, a criança surda terá o desenvolvimento da língua conforme o esperado (normal).

O processo de aquisição da linguagem, geralmente, ocorre nos primeiros anos de vida, de forma natural. A interação comunicativa entre o bebê e os pais, familiares e/ou pessoas que com ele convivem possibilita que o processo de aquisição da linguagem aconteça sem maiores esforços, em pouco tempo. [...] Além disso, o processo de aquisição da linguagem por crianças acontece de forma semelhante em diferentes línguas e não depende da modalidade de língua a que estão expostas: auditivo-oral ou visuoespacial (CRUZ, 2011, p. 32).

Cruz (2011) esclarece que a aquisição é um processo que ocorre somente para a primeira língua ou língua materna ou natural. Para a segunda língua, encontramos o processo de aprendizagem. Para os surdos, a sua primeira língua é a língua de sinais - no Brasil, a 
língua brasileira de sinais (Libras). A partir da aprendizagem da segunda língua, o Português, em sua modalidade escrita, caracteriza-se a abordagem bilíngue.

Em um ambiente educacional bilíngue para surdos é a partir da primeira língua (neste caso, a língua de sinais) que a escola planeja o processo de ensino-aprendizagem e intervenções para a aprendizagem da segunda língua (neste caso, a língua portuguesa em sua modalidade escrita).

Este perfil contemporâneo de escola bilíngue corrobora a ideia de que o ambiente educacional bilíngue favorece a comunicação e o desenvolvimento integral das crianças surdas. Os novos alunos, crianças surdas implantadas, são uma realidade cada vez mais presente no ambiente escolar.

Inimaginável há alguns anos, a necessidade de uma Educação Bilíngue é enunciada também por um grupo de profissionais da área médica e fonoaudiológica, que a defende como estratégia concomitante ao Implante Coclear. A necessidade de expor a criança surda à Língua de Sinais, além da reabilitação auditiva e oral é verificada no discurso de alguns profissionais.

O quadro abaixo evidencia esses discursos de profissionais da área médica / fonoaudiológica, no relato dos pais, separados entre aqueles que defendem a exclusividade do Implante Coclear e da necessidade de oralização dos surdos, e, aqueles de defendem a simultaneidade do Implante Coclear e da Educação Bilíngue.

Quadro 7: Discursos médicos e fonoaudiológicos sobre o IC

\begin{tabular}{|c|c|}
\hline $\begin{array}{c}\text { Profissionais que defendem a exclusividade } \\
\text { do Implante Coclear e oralização da } \\
\text { criança surda }\end{array}$ & $\begin{array}{l}\text { Profissionais que defendem a } \\
\text { simultaneidade do Implante Coclear e } \\
\text { da exposição da criança surda à Libras }\end{array}$ \\
\hline $\begin{array}{l}\text { Aí comecei a conhecer, só que eu fiquei assim } \\
\text { em dúvida com relação ao aparelho e da língua } \\
\text { de sinais. [...], ela pega muito no pé. Ela falava } \\
\text { muito assim: ai, C., você tem certeza que é } \\
\text { isso que você quer, porque isso vai } \\
\text { atrapalhar muito a fala dela, eu fiquei } \\
\text { sabe? Eu até converso muito isso muito com a } \\
\text { S. É tanto que eu estava com a cabeça meio } \\
\text { bagunçada, em dúvida. (Entrevista 4) }\end{array}$ & $\begin{array}{l}\text { Aí no Hospital } X \text {, onde fez o Implante, a } \\
\text { fono na época, ela falou de sinais, } \\
\text { Libras, né, nem tudo está perdido, ele } \\
\text { vai conseguir se virar. Foi aí que a gente } \\
\text { começou a se interessar, o que é sinais, o } \\
\text { que é Libras. (Entrevista 8) }\end{array}$ \\
\hline $\begin{array}{l}\text { Em algumas cadeiras da otorrinolaringologia, } \\
\text { eles são um pouco contrários à língua de }\end{array}$ & $\begin{array}{l}\text { A primeira fono mesmo que eu te falei } \\
\text { que fez o exame lá que falou é perda }\end{array}$ \\
\hline
\end{tabular}




\begin{tabular}{|c|c|}
\hline $\begin{array}{l}\text { sinais, a gente, não sei se você viu isso deles } \\
\text { dizerem, não, não é para usar, não é para ir } \\
\text { por esse caminho. (Entrevista 2) } \\
\text { Mas tem mesmo a fonoaudióloga do Implante, } \\
\text { ela sempre fala que como se ajudasse ela a } \\
\text { deixar mais preguiçosa para o Implante, a } \\
\text { língua de sinais. (Entrevista 2) }\end{array}$ & $\begin{array}{l}\text { profunda, ela falou agora você escolhe, } \\
\text { você tem dois caminhos: ou vai para } \\
\text { Libras e acabou a audição ou vai para a } \\
\text { audição e acabou Libras. Ela já } \\
\text { determinou. Só que aí, engraçado que } \\
\text { depois justamente a outra fono, que é a } \\
\text { que faz a terapia mesmo, ela falou, } \\
\text { quando eu sugeri que o tempo estava } \\
\text { passando e eu não conseguia passar nada } \\
\text { para ele, ela falou não, põe ele numa } \\
\text { escola e não vejo problema nenhum, e } \\
\text { uma coisa jamais vai impedir a outra. } \\
\text { (Entrevista 3) }\end{array}$ \\
\hline
\end{tabular}

Quadro elaborado pelas autoras deste artigo, com trechos das entrevistas.

Asfalas divergentes dos profissionais, em muitos momentos, parecem mais confundir do que auxiliar os pais. Por isso, o relato de uma das mães: "É tanto que eu estava com a cabeça meio bagunçada, em dúvida". A mudança possível no discurso de uma parcela da comunidade médica/fonoaudiológica parece vir como resposta à luta da comunidade surda, que há anos se empenha pelo reconhecimento da importância da Língua de Sinais para o desenvolvimento das pessoas surdas, como afirma Góes:

sobretudo nas situações de surdez congênita ou precoce em que há problemas de acesso à linguagem falada, a oportunidade de incorporação de uma língua de sinais mostra-se necessária para que sejam configuradas condições mais propícias à expansão das relações interpessoais, que constituem o funcionamento nas esferas cognitiva e afetiva e fundam a construção da subjetividade (GÓES, 1996, p. 38).

Haveria nestes discursos fonoaudiológicos e médicos uma mudança paradigmática, que reflete o fato destes profissionais terem se mobilizado pela luta daquele grupo minoritário que, assim, passou a respeitar suas convicções? A nosso ver, a inserção da disciplina de Libras nos cursos de fonoaudiologia determinada pelo Decreto 5626 de 2005, pode ter sido uma das responsáveis por tal mudança, pelo menos em alguns contextos. Além disso, pesquisas têm demonstrado que crianças implantadas expostas à Língua de Sinais apresentam melhor desenvolvimento linguístico, inclusive da Língua Oral.

Uma pesquisa de Melo et al (2012) comparou as habilidades auditivas e de linguagem em quatro crianças implantadas; duas eram filhas de pais surdos, inseridas, portanto em 
ambiente bilíngue, e duas de pais ouvintes, incluídas em ambiente exclusivamente oral. As crianças filhas de pais surdos apresentaram, três anos após o Implante, melhor desempenho auditivo e em linguagem oral, quando comparadas às outras duas crianças.

\footnotetext{
Em termos de desenvolvimento linguístico, as crianças " $\mathrm{A}$ " e "B" (ambiente bilíngue), após três anos de uso do IC eram capazes de construir frases de mais de cinco palavras, usando elementos conectivos, conjugando verbos, utilizando plurais, ou seja, apresentando fluência na linguagem oral. As crianças inseridas em ambiente oral ("A1" e "B1"), após cinco anos de uso do IC, ainda não atingiram esta habilidade (MELO et. al, 2012, p. 478-9).
}

Embora a conclusão das autoras seja de que "em um ambiente educacional adequado que ofereça a linguagem oral, o conhecimento da língua de sinais não afeta negativamente a evolução das habilidades auditivas e de linguagem" (idem, p. 479), a partir de nossas experiências, podemos sugerir que o ambiente bilíngue favoreceu a aquisição da linguagem oral.

Outra pesquisa de Quadros, Cruz e Pizzio (2012) avaliou o desempenho linguístico de crianças surdas usuárias de Implante Coclear e ouvintes expostas a contexto bilíngue e bimodal (Libras e Língua Portuguesa), utilizando tarefas de memória fonológica. Os grupos avaliados eram assim compostos: 1. Uma criança surda, usuária de IC, filhas de pais ouvintes; 2. Crianças surdas, usuárias de IC, filhas de surdos e com algum contato com a Libras; 3. Crianças ouvintes filhas de pais surdos. O resultado mostrou que o desempenhoda criança surda usuária de Implante Coclear, filha de pais surdos, e, portanto, com acesso irrestrito à Libras foi semelhante ao do grupo de crianças bilíngues bimodais ouvintes. Já as crianças surdas filhas de pais ouvintes, usuárias de Implante Coclear, que possuem acesso restrito à Libras, foi constatado que o seu desempenho é inferior aos dois outros grupos. As autoras concluíram que:

\footnotetext{
A análise dos resultados revela que a criança surda com implante coclear com acesso irrestrito à Libras apresenta desempenho muito próximo das crianças bilíngues bimodais ouvintes na Libras e no Português, resultado diferente das crianças surdas com implante coclear com acesso restrito à Libras, que apresentam desempenho inferior no Português e nos padrões fonológicos da Libras, sendo que mesmo com acesso restrito à Libras estas crianças conseguem atingir desempenho melhor na Libras. Com base nisso, o estudo realizado indica a importância de garantir às crianças surdas com implante coclear o acesso irrestrito à Libras (QUADROS, CRUZ e PIZZIO, 2012, p. 185).
} 


\section{LIBRAS E IMPLANTE COCLEAR: CONTRADIÇÃO OU COMPLEMENTARIDADE?}

Ambas pesquisas apontam para o mesmo resultado, de que a Libras é um elemento favorável ao desenvolvimento da linguagem oral em crianças implantadas. Portanto, os pais que fizeram esta opção pelos dois (IC e Libras) podem ter se guiados por comentários de profissionais e também de pais e surdos que fizeram esta opção combinada. Um novo discurso, portanto, parece permear a realidade da surdez e da educação dos surdos, não mais impondo uma única possibilidade que exclui a outra, mas propondo a concomitância destas possibilidades.

\section{EDUCAÇÃO BILÍNGUE E IMPLANTE COCLEAR: ESCOLHAS E DÚVIDAS}

Como refletimos anteriormente, fazer o filho real se aproximar do idealizado é o que os pais almejam. Possibilitar a comunicação é um dos desejos dos pais, e este desejo direciona as suas escolhas, assim como o de tornar seus filhos iguais a si próprios - ouvintes e falantes. A experiência com ambas as línguas é relatada como possível e benéfica para a comunicação entre eles e seus filhos, como vemos nesses excertos:

Quadro 8: Língua de Sinais

Então o Implante serve o dia inteiro só que na hora do banho elas precisam falar comigo, na hora de dormir, tem horas que não dá, elas precisam conversar comigo. Elas acordam tipo, 7h, eu vou por o Implante 9h. Então nesse intervalo a gente fala de outra maneira, que é a língua de sinais. (Entrevista 1)

Então a gente tem percebido realmente que ela tem se sentido mais a vontade com 0 sinal, com a Libras. (...) então a gente não tem essa visão de que isso, uma coisa ia atrapalhar a outra assim. (Entrevista 2)

Nossa preocupação era como é que ele ia se virar, como ele ia se comunicar com as pessoas. E ele na primeira semana a gente já viu resultado. Primeira semana que ele teve contato com a Libras ele já desenvolveu muito. Aí a gente viu que tava no caminho certo mesmo. (Entrevista 3)

E para educar ele foi um diferencial enorme porque realmente não tinha como educar ele. A gente estava recebendo reclamação da escola, que ele tava, da creche, elas reclamavam que não conseguiam conversar com ele, ele não prestava atenção em nada, para ele, ele vivia naquele mundo. Aí em casa a gente tentava, era sim e não, sim e não, 
não saia disso. O que estava muito difícil, Aí com a Libras a gente já conseguiu falar com ele. (Entrevista 3)

Então foi um resultado assim, assim, não estou vendo assim 100\% de fala, mas ela já está falando alguma coisa, estou vendo algum resultado do Implante, então está sendo muito importante para ela. E Libras ela entende super bem Libras depois que a gente começou aqui. (Entrevista 4)

Depois que a L. começou a ter contato com as Libras principalmente na Escola Xc que isso era direto, ela se tornou uma criança totalmente diferente. A comunicação que ela gosta é por Libras. (...) Mas a primeira opção dela é por Libras. A fala não é uma opção que ela, muito pelo contrário, porque ela não tem essa, o Implante não deu essa possibilidade para ela dela processar a fala através do sinal que ela recebe. (Entrevista 5)

Mas já peguei costume da língua de sinais. Então eu uso tanto a voz como sinais até porque meu filho é surdo. Então se eu estou conversando com um ouvinte, eu não acho justo ele ficar de lado, então eu uso sinais para falar também para ele entender o que está sendo falado. (Entrevista 6)

Então quando ele está com os amigos dele, são surdos, ele só faz as Libras, dificilmente ele fala, mas às vezes ele chama porque ele acha que vai ouvir. Às vezes ele chama, mas quando ele tá assim, ele conversa. (...) Então ele já sabe distinguir quem é surdo e quem não é, quem e ouvinte. (Entrevista 7)

Ele sacou que ele está aqui na escola, prevalece aqui sinais. Fora, ele sabe que lá fora 0 pessoal vai chamar ele pelo nome. Em uma reunião familiar, o pessoal chama pelo nome, ele também consegue se sair, consegue socializar. Então ele tá, assim, você percebe que não é uma criança que está querendo se comunicar e não consegue, não está nervosa, nada. Ele está conseguindo levar as duas línguas aí. (Entrevista 8)

Quadro elaborado pelas autoras deste artigo, com trechos das entrevistas.

Nestes excertos, os pais evidenciam que o ponto principal para eles, é a comunicação com os filhos, poderem compreendê-los e serem compreendidos. Quando um bebê nasce, ele é imerso na linguagem e a língua dos pais vai, aos poucos, atribuindo significado às experiências do bebê. Ao mesmo tempo em que adquire a linguagem, vai se constituindo como sujeito. A linguagem não se instala no bebê em um momento único, ela ocorre num processo, assim como a constituição da subjetividade. Mas, “[...] é necessária a ausência da mãe para que ela possa se nomeada. A linguagem torna algo presente na sua ausência, e esta é 
sua condição de possibilidade: a distância" (CASTRO, 1992, p. 27). É na ausência da mãe, nos pequenos ou longos momentos de frustração, que o bebê sente a necessidade da nomeação, de chamá-la, de se enunciar. Ao se apropriar da língua, passa a poder nomear as coisas ao seu redor. Mas, nos casos de bebês com surdez profunda e pais ouvintes, como é possível que isso ocorra pela língua que inunda o ambiente? A língua materna é definida como a língua na qual o sujeito se constitui, "língua em que o sujeito se representa, de uma escolha prevalente, determinada pelos restos arcaicos da relação linguística com a sua mãe" (JERUSALINSKY, 2008, p. 76). No caso de bebês surdos, embora se criem possibilidades de comunicação rudimentares, como pelos gestos, por exemplo, somente uma língua estruturada é capaz de permitir a real constituição de um sujeito e uma relação de significação do mundo.

A compreensão desta necessidade parece já estar clara para os pais entrevistados nesta pesquisa, uma vez que todos atribuem à Língua de Sinais um lugar de importância na vida dos filhos. Mas, há de se admitir que tal aceitação demanda esforço dos pais, uma vez que eles têm que aprender uma nova língua ao invés de "ensinar" sua língua aos filhos. É uma inversão da ordem comum dos acontecimentos. Os pais têm que aprender uma língua com profissionais, ao mesmo tempo em que os filhos também a adquirem. Em muitos momentos, aprendem também com seus próprios filhos.

O desejo, porém, de possibilitar aos filhos também a aquisição de sua língua (a dos pais) é manifesto por eles.

Vejamos como argumentam sobre isso:

\section{Quadro 9: Sobre o futuro}

A gente tem que dar todas as opções que a gente puder para a C. Quando ela for maior, aí a opção será dela. Se ela quiser optar por utilizar um Implante, se ela não quiser, vai ser só a parte de sinais, vai ser uma opção dela. A gente queria dar todas as opções para ela. (Entrevista 2)

E eu quero que ela seja independente, entendeu? Por isso eu estou correndo atrás, porque quando ela crescer ela falar: - minha mãe correu atrás, fez as coisas por mim. Que ela seja independente. (Entrevista 4)

Eu optei implantar o P. porque eu não tenho o direito de tirar isso dele. Se Deus deu o dom do médico fazer com que meu filho ouça, porque não tentar? Se lá na frente ele não 
quiser usar, é uma coisa que ele pode tirar. Mas se ele quiser usar e der certo, ele vai me agradecer. Agora e se eu não tentar? E lá na frente meu filho olhar para mim e dizer: você poderia ter tentado, e você não tentou. Isso ia me doer muito, por isso que eu fiz. (Entrevista 6)

Ah, mas e depois? Ah, depois mais para frente ele vai perguntar: mãe, porque você não fez? Ela não vai ter a resposta. (...) depois vai me cobrar por uma coisa que coube a mim decidir. Porque a criança não decide. Ele vai decidir mais para frente. (Entrevista 7)

Na verdade a decisão nossa hoje do $N$. estar implantado, é para que amanhã ele fale assim, olha eu não quero esse Implante, eu quero ser surdo mesmo, não quero ouvir. Mas pelo menos meus pais me deram a opção, de repente, ouvir pelo menos um retorno, algum barulho de alguma coisa. (Entrevista 8)

Quadro elaborado pelas autoras deste artigo, com trechos das entrevistas.

Semelhantes, os discursos destes pais revelam que a decisão pelo Implante se fez na tentativa de dar aos filhos a possível "audição" e a aquisição da "fala", que a tecnologia do Implante Coclear promete. Apontam em seus enunciados o receio de que, se não o fizessem, poderiam ser cobrados pelos filhos no futuro. Mais do que torná-los portadores de "ouvidos biônicos", reféns da normalização imposta pela medicina, parecem demonstrar uma genuína preocupação com as possibilidades de desenvolvimento acadêmico, social e profissional dos filhos. $\mathrm{O}$ fato de não negarem a eles a possibilidade concomitante de uma educação bilíngue reflete o investimento em todas as formas que permitam a seus filhos uma vida digna.

\section{CONSIDERAÇÕES FINAIS}

Considerando a decisão das famílias por optarem por duas abordagens distintivas na educação e no desenvolvimento de seus filhos surdos e considerando os apontamentos teóricos, permitimo-nos inferir que a aproximação e, até mesmo, o trabalho em conjunto da abordagem médico/fonoaudiológico e da abordagem educacional/pedagógica favoreceram a emergência de um novo sujeito sociocultural: "a criança surda implantada bilíngue". O surgimento deste novo sujeito permite que novas relações, atividades e situações sejam 
cenários múltiplos, ricos e diversos para o desenvolvimento integral do indivíduo e da sua subjetividade.

Nestes cenários, o "novo sujeito", que tem como sustentação um "novo discurso", potencializa em sua subjetividade uma ferramenta/uma técnica importantíssima: o cuidado, o conhecimento, o governo de si mesmo. Por um lado, concluímos que as famílias tomaram sua decisão, pelo uso das duas técnicas, como medida de bem estar e de cuidado para com o filho, visando minimizar males ou sofrimentos futuros. Por outro, que esta opção configura-se como um novo laço subjetivo entre a mãe e/ou o pai, resgatando a identificação familiar. Concluímos que subjetividade e identidade, subjetivação e identificação, como produtos e processos correlatos manifestam-se como autênticos em nossa amostra e não sob o véu da “coisificação" (objetificação/reificação).

Ao optarmos por uma análise psicanalítica e hermenêutica neste artigo, confluímos pontos em comum nestas abordagens, na tentativa de compreender o modelo inusitado e atual que emerge das práticas atuais na educação / reabilitação dos surdos. Esse diálogo entre as duas teorias parece difícil, porém o ponto de confluência se fez na observação da influência da cultura nos modos de vida das pessoas. Se para Freud, ela se faz pelo caminho da repressão, para Foucault, se realiza pela instauração de uma relação de poder. Para Freud, a escolha dos pais é determinada pela fantasia idealizada de um filho normal e para Foucault pelos discursos e práticas normativos e normalizadores da atualidade. Ambas argumentações puderam ser analisadas e revisitadas e pode-se concluir que as motivações e escolhas familiares são determinadas pela cultura que modela e direciona a subjetividade dos indivíduos.

As famílias optam por tentar e oferecer à criança todas as técnicas e tecnologias normalizadoras da atualidade para que, no futuro, as crianças surdas possam optar ou até mesmo criticar estas possibilidades e, assim, exercer sua subjetividade com independência. Ao mesmo tempo, reconhecem a Língua de Sinais como elemento gerador de uma comunicação efetiva que possibilita aprendizagem escolar e a formação identitária e subjetiva. Enfim, de forma corajosa e autêntica, optaram pelas duas abordagens cientes de sua responsabilidade como pais, fornecer condições de uma vida autônoma para seus filhos.

\section{LIBRAS E IMPLANTE COCLEAR: ¿CONTRADICCIÓN O COMPLEMENTARIEDAD?}




\title{
Resumen
}

Este artículo tiene como objetivo determinar las razones por las que algunos padres de las personas sordas que hacen cooptación por la cirugía de implante coclear y la exposición a Lengua Brasileña de Señas. La metodología de investigaciónesel enfoque crítico histórico y el análisis psicoanalítico-hermenéutica 8 entrevistas con padres y/o madres de niños matriculados en una escuela bilingüe para sordos. Los autores que se basan los análisis son Freud y otros autores de la psicoanálisis, loscuales nos ayudan a comprenderlos motivos subjetivos que direccionanlos deseos y decisiones de los padres; y, también, Michel Foucault que, con sus estudios, nos ayuda a comprender el surgimiento de nuevos sujetos y discursos de verdad. Nuestra conclusión es de que, al optar por un procedimiento duplo y simultáneo de las posibilidades, las familias consideran éstas complementares y, con esto, están ejerciendo su papel sociocultural como padres. Los resultados apuntan la emergencia de un nuevo sujeto sordo, bilingue con implante coclear, que requiere nuevas posibilidades educativas.

Palabras-clave: Implante Coclear; Educaciónbilingüe Para Sordos; Psicoanálisis; Subjetividad; Análisis De Discursos

\section{LIBRAS AND COCHLEAR IMPLANT: CONTRADICTION OR COMPLEMENTARITY?}

\begin{abstract}
This paper analyses the answers for the interviews carried out with deaf children's parents about their decision for the rehabilitation and education of their kids, decision which is marked by the simultaneous choice of submitting them to cochlear implant surgery and the exposition to the Brazilian Sign Language. The research's methodology adopted the historical criticism and the psychoanalysis - hermeneutic analysis for the eight interviews carried out with parents of the children who are regularly enrolled in a bilingual school for deaf children. We tried to analyze the reasons that boosted this specific decision making by parents. The authors that support our research are Freud, and others from psychoanalysis, who helped us understand the subjective motivation boosting parents' desires and decision making actions;
\end{abstract}


Also, Michel Foucault whose studies helped us comprehend a new human subject appearance and the truth discourse. Our conclusions are that when parents choose this double and simultaneous approach, which families consider as complementary, families are acting their social and cultural roles as parents. The outcomes show us the emergency of a new deaf subject, the bilingual with a Cochlear Implant, that requires some new educational possibilities.

Keywords: Cochlear Implant; Bilingual Education For The Deaf; Psychoanalysis; Subjectivity; Discourse Analysis

\section{REFERÊNCIAS}

BRASIL, Portaria $N^{o} 18$ do Ministério Saúde de 10 de junho de 2014. Disponível em http://bvsms.saude.gov.br/bvs/saudelegis/sctie/2014/prt0018_10_06_2014.html. Acesso em 20 de abril de 2015.

Decreto $N^{\circ} 5626$ da Casa Civil da Presidência da República de 22 de dezembro de 2005. Disponível em http://www.planalto.gov.br/ccivil_03/_ato20042006/2005/decreto/d5626.htm. Acessado em: 03 Nov. de 2015.

CANGUILHEM, Georges. O normal e o patológico. Tradução de Maria Thereza Redig de Carvalho Barrocas. $4^{a}$ ed. Rio de Janeiro: Forense Universitária, 1995.

CASTRO. Eliana M. Psicanálise e linguagem. São Paulo: Ática, 1992.

CRUZ, Carina Rebello. Avaliação e intervenção da linguagem na criança surda em uma abordagem bilíngue. In: MOURA, M. C., CAMPOS, S. R e VERGAMINI, S. A. (org.). Educação para surdos: práticas e perspectivas II. São Paulo: Santos, 2011.

FOUCAULT, Michel. Os Anormais:curso no College de France (1974-1975). Michel Foucault: tradução Eduardo Brandao. São Paulo: Martins Fontes, 2001.

. A sociedade punitiva. IN: Foucault, Michel. Resumo dos cursos do Collège de France (1970-1982). Tradução Andrea Daher; Consultoria Roberto Machado. Rio de Janeiro: Jorge Zahar Ed., 1997ª

É preciso defender a sociedade. IN: Foucault, Michel. Resumo dos cursos do Collège de France (1970-1982). Tradução Andrea Daher; Consultoria Roberto Machado. Rio de Janeiro: Jorge Zahar Ed., 1997b. 
Subjetividade e verdade. IN: Foucault, Michel. Resumo dos cursos do Collège de France (1970-1982). Tradução Andrea Daher; Consultoria Roberto Machado. Rio de Janeiro: Jorge Zahar Ed., 1997c.

A hermenêutica do sujeito. IN: Foucault, Michel. Resumo dos cursos do Collège de France (1970-1982). Tradução Andrea Daher; Consultoria Roberto Machado. Rio de Janeiro: Jorge Zahar Ed., 1997d.

FREITAS, Maria Teresa. A perspectiva sócio-histórica: uma visão humana na construção do conhecimento. IN: KRAMER, Sonia (et al.) Ciências Humanas e pesquisa: leituras de Mikhail Bakthin.2 ed. Coleção questões da nossa época. São Paulo: Ed. Cortez, 2007.

FREITAS, M. T., JOBIM e SOUZA, S. e KRAMER, S. (org.). Bakhtin. $2^{\text {a }}$ ed. Coleção questões de nossa época. São Paulo: Cortez, 2007.

FREUD, Sigmund. A denegação. Edição Standard Brasileira das Obras Psicológicas completas de Sigmund Freud. Volume XIX. Rio de Janeiro: Imago, 1976.

GÓES, Maria Cecília R. Linguagem, surdez e educação. Campinas: Autores Associados, 1996.

JERUSALINSKY, Alfredo. Saber falar: Como se adquire a língua? Petrópolis: Vozes, 2008.

LIBERALESSO, Paulo; LIBERALESSO, Maria Christina N. Estudo etiológico e legislativo sobre surdez. Curitiba: UTP, 2011.

MANNONI, Maud. A criança retardada e a mãe. $2^{\mathrm{a}}$ ed. São Paulo: Martins Fontes, 1988.

MARQUES, Luciana Pacheco. O filho sonhado e o filho real. Revista brasileira de Educação Especial.Piracicaba, v. 2, p. 121-125, 1995.

MELO, Tatiana Mendes de et al. Audição e linguagem em crianças deficientes auditivas implantadas inseridas em ambiente bilíngue: um estudo de casos. Rev. soc. bras. fonoaudiol., São Paulo, v. 17, n. 4, p. 476-481, Dez. 2012. http://dx.doi.org/10.1590/S151680342012000400019. Acesso em: 03 Nov. de 2015.

QUADROS, Ronice Muller de. Educação de surdos: A aquisição da linguagem. Porto Alegre: Artes Médicas, 1997.

QUADROS. M.. de; CRUZ, C. R..; PIZZIO, A. L. Memória fonológica em crianças bilíngues bimodais e crianças com implante coclear. ReVEL, v. 10, n. 19, 2012. [http://www.revel.inf.br/pt]. Acesso em: 03 Nov. de 2015.

REZENDE, Patrícia L. F. Implante coclear: normalização e resistência surda. Curitiba: CRV, 2013.

ROUDINESCO, E; PLON, M.Dicionário de Psicanálise. Rio de Janeiro: Jorge Zahar, 1998. 
THOMA, Adriana da S., et.al. Relatório sobre a Política Linguística de Educação Bilíngue Língua Brasileira de Sinais e Língua Portuguesa. Disponível em:

http://www.bibliotecadigital.unicamp.br/document/?down=56513. Acesso em: $02 \mathrm{Abr}$. de 2014.

VEIGA-NETO, Alfredo. Foucault \& a Educação. Belo Horizonte: Autêntica, 2005.

Data de recebimento: $27 / 05 / 2015$

Data de aceite: $27 / 10 / 2015$ 